\title{
OSOBLIWE SŁOWNICTWO SZESNASTOWIECZNYCH LEKSYKONÓW (NA WYBRANYCH PRZYKŁADACH NAZW RZEMIEŚLNIKÓW)
}

Szesnaste stulecie jest okresem bardzo szybkiego rozwoju wszelakiego piśmiennictwa i literatury, co związane było niewątpliwie z nowym sposobem upowszechniania książki - z drukiem (Bajerowa 1980). W szybkim tempie wzbogaca się również polskie słownictwo, a w tym oczywiście także leksyka dotycząca gospodarki, rolnictwa i rzemiosła.

Przyglądałam się już leksyce dotyczącej rzemiosła, a dokładnie funkcjonującym w XVI stuleciu nazwom rzemieślników (Migdał 2015; 2016). W tym celu sięgałam po Stownik polszczyzny XVI wieku, który odnotowuje prawie całość ówczesnego słownictwa z różnych dziedzin $^{1}$. Do ekscerpcji wykorzystałam wyłącznie opublikowane dotychczas tomy słownika, czyli do hasła roztyrknać $c^{2}$. Pozornie proste zadanie wypisania z SPXVI nazw rzemieślników okazało się jednak nie takie proste i oczywiste. Pojawia się bowiem kłopot ze ścisłym ustaleniem podstawowych pojęć, co należy zaliczyć do rzemiosła i kto jest rzemieślnikiem³.

Ogółem w 36 tomach SPXVI znalazło się na podstawie źródeł 195 nazw rzemieślników. W tym zbiorze sporą grupę stanowią hasła odnotowane w słowniku wyłącznie z ówczesnych zbiorów leksykograficznych Jana Murmeliusza ${ }^{4}$, Franciszka Mymera ${ }^{5}$, Bartłomie-

\footnotetext{
${ }^{1}$ Oczywiście, zdaję sobie sprawę z niedoskonałości SPXVI. Autorzy słownika nie mogli ekscerpować wszystkich szesnastowiecznych tekstów, ale opracowali kanon źródeł, które według nich są reprezentatywne dla literatury i szeroko rozumianego piśmiennictwa XVI stulecia. Jednak i w tym kanonie brakuje bardzo wielu choćby przykładowych - utworów z różnych dziedzin piśmiennictwa (głównie dotyczy to tzw. tekstów użytkowych).

${ }^{2}$ Powtórzę to, o czym już kilkakrotnie pisałam, że bardzo trudne, jeśli nie niemożliwe są badania pozostałego materiału zgromadzonego w Pracowni SPXVI. Indeksy haseł oraz kartoteka nie są jeszcze wyposażone w znaczenia, aby więc znaleźć ewentualne nazwy rzemieślników z nieopracowanych liter alfabetu, trzeba by przeczytać wszystkie cytaty i na ich podstawie określić znaczenia. Praca ta przekracza możliwości jednej osoby.

${ }^{3}$ Pisałam o tym w: Migdał 2016.

4 Jan Murmeliusz, Dictionarius [...] Rozmaitych rzeczy wokabuty tacińskie z niemieckiem i polskim wykładem, Kraków 1528.

${ }^{5}$ Franciszek Mymer, Dictionarium trium linquarum: Latino, Teutonice et Polonice, Kraków 1541; też Kraków 1528.
} 
ja z Bydgoszczy ${ }^{6}$, Jana Mączyńskiego ${ }^{7}$, Ambrożego Calepina ${ }^{8}$ i Mikołaja Volckmara ${ }^{9}$. Grupa tego typu określeń liczy 67 haseł, co stanowi aż około 35\% całości.

Są to następujące nazwy rzemieślników ${ }^{10}$ :

bartodziej 'pszczelarz, bartnik (właściwie: wycinacz barci)' BartBydg', barwierka '... golarka, fryzjerka' Mącz, Calep,

baumistrz 'budowniczy, mistrz ciesielski' Mącz,

blachmistrz 'blacharz, rzemieślnik wyrabiający blachy lub wykonujący przedmioty z blachy; płatnerz' Calep,

blachownik 'blacharz, rzemieślnik wyrabiający blachy lub wykonujący przedmioty z blachy; płatnerz' Mącz,

cegielnik 'wyrabiający cegłę' BartBydg, Mącz, Murm, Mym,

cieszykamień 'rzemieślnik zajmujący się obróbką kamienia; kamieniarz' Volck,

cieśla 'rzemieślnik zajmujący się obróbką kamienia, kamieniarz' Mącz,

cymbatownik 'rzemieślnik wyrabiający cymbały' Mącz,

czaszarz 'rzemieślnik robiący naczynia' Mącz,

czepiennik 'rzemieślnik wyrabiający czepce' BartBydg,

dlubacz 'ten, który drąży, żłobi' Calep,

drapacz ' golarz, golibroda, balwierz' Mącz,

dreznar 'tokarz' BartBydg, Murm,

drożnik 'ten, co toczy, dłubie, rzeźbi w drzewie lub w metalu; tokarz' Mącz,

drożyciel 'rzeźbiarz, rytownik, snycerz' Mącz,

farbarz 'rzemieślnik barwiący tkaniny' Mącz,

farbierz 'rzemieślnik barwiący tkaniny', 2. 'wałkarz, folusznik' Mącz,

formarz 'rzemieślnik tworzący, wyrabiający formy, wzory, wykrawający ryciny, obrazy'

Mącz,

golacz 'ten, który goli, fryzjer' Calep,

golicz 'ten, kto goli, fryzjer' (z czes) Mym,

gramplerz 'rzemieślnik zajmujący się czesaniem i drapaniem wełny' Calep,

grubarz 'robotnik zajmujący się pracami ziemnymi..,' Mym,

guntownik 'robotnik pokrywający dachy gontem' Calep,

hutarz 'hutnik pracujący przy wytapianiu żelaza lub szkła' Mącz,

igielnik 'rzemieślnik wyrabiający igły, szpilki, haftki' BartBydg,

jatnik 'człowiek stawiający prowizoryczne budowle' Mącz,

jedwabnik 'człowiek wyrabiający jedwabne tkaniny' Mącz,

kichlarz 'człowiek trudniący się wypiekiem słodkich ciast (z niem.)' Mym, BartBydg,

kiełbaśnik 'ten, kto wyrabia kiełbasy’ Mącz, Calep,

kołacznik 'piekarz zajmujący się przyrządzaniem ciast' Mącz,

klejsmir 'rzemieślnik trudniący się obróbką żelaza (z niem.)' BartBydg,

${ }^{6}$ Bartłomiej z Bydgoszczy, Vocabularius ex Calepino, Breuiloquo et Mamotrecto reccolectus..., 1532.

7 Jan Mączyński, Lexicon latino-polonicum, Królewiec 1564.

${ }^{8}$ Ambrosius Calepinus, Dictionarium decem linguarum, Lugdunum 1588.

${ }^{9}$ Mikołaj Volckmar, Dictionarium trilingue tripartitum, Gdańsk 1596.

${ }^{10}$ Interesują mnie wyłącznie znaczenia, które odnoszą się do rzemieślników.

11 Wykaz skrótów znajduje się na końcu artykułu. 
kobiertnik 'ten, kto wyrabia kobierce' Calep, kobierzecznik 'ten, kto wyrabia kobierce' Calep, kocielnik 'rzemieślnik wyrabiający kotły; kotlarz' Mącz, BartBydg, koleśnik 'rzemieślnik wyrabiający wozy' Mącz, Calep, kotewnik 'rzemieślnik wyrabiający kotwice' Volck, krupiarz 'ten, kto robi krupy, kaszę, obtłukuje ziarno' Mącz, leglarz 'rzemieślnik wyrabiający beczki i inne naczynia drewniane' Murm, Mym, BartBydg, lekarz 'człowiek sporządzający lekarstwa' Mącz, tamacz 'ten, który kruszy, niszczy' Mącz, a. 'robotnik wydobywający lub obrabiający kamienie', synonim: kamienny cieśla, tatacz 'naprawiający zniszczoną odzież' Mącz, Calep, synonim: krawiec, mieczerz 'rzemieślnik wyrabiający miecze, płatnerz, tu: zatrudniony przy ich ostrzeniu i polerowaniu' Murm, BartBydg,

miedziownik 'rzemieślnik wyrabiający przedmioty z miedzi lub mosiądzu, spiżu, brązownik' Volck,

misarz 'rzemieślnik wyrabiający miski i talerze oraz być może części zbroi okrywające stawy barkowe i kolanowe zwane miskami’ Mym, BartBydg,

młotnik 'robotnik kujący młotem' Mącz,

namiotnik 'rzemieślnik wykonujący namioty' Mącz,

nożownik 'rzemieślnik wyrabiający noże i inne narzędzia tnące' Murm, Mym, BartBydg, Mącz, Volck, obraźnik 'rzeźbiarz, snycerz' Murm, BartBydg, Mącz, Volck, okiennik 'rzemieślnik zajmujący się wyrobem okien' Murm, BartBydg, olejnik 'ten, kto trudni się wyrobem lub sprzedażą oleju' Murm, BartBydg, Mącz, olejownik 'ten, kto trudni się wyrobem lub sprzedażą oleju' Calep, oliwnik 'ten, kto trudni się wyrobem oleju' Mącz, pargamennik 'rzemieślnik wyrabiający pergamin’ Murm, Mym, BartBydg, Mącz, Volck, pastetarz 'rzemieślnik wypiekający wykwintne potrawy z ciasta' Volck, pasztetnik 'rzemieślnik wypiekający wykwintne potrawy z ciasta' Calep, Volck, piecownik 'rzemieślnik stawiający piece' Mącz, piernikarz 'ten, kto zajmuje się pieczeniem i sprzedażą pierników' Calep, pobielacz 'tynkarz' Mącz, Calep, podeszwacz 'wytwórca obuwia w postaci podeszwy przywianej do stopy rzemykami lub sznurkami, sandałów' Murm, BartBydg, polerz 'ten, kto odświeża zużytą, starą odzież' Calep, postrzygaczka 'rzemieślniczka wykańczająca sukno' Mącz, powroźnik 'rzemieślnik wyrabiający powrozy, też ten, kto je sprzedaje' Murm, Mym, BartBydg, Mącz, Calep, prasownik 'człowiek obsługujący prasę, a. drukarz' Mącz, Calep, przędacz 'ten, kto zajmuje się wyrobem przędzy' BartBydg, przychędożca 'ten, kto coś odświeża, odnawia' Calep, synonim: polerz, pszczelarz 'człowiek zajmujący się hodowlą pszczół' Mącz, Calep, pytelnik 'pracownik młyna pytlujący mąkę' Mącz. 
Chciałabym przyjrzeć się leksykograficznym dziejom tych nazw. SPXVI odnotował te nazwy wyłącznie z ówczesnych leksykonów, jednak ich historia nie zawsze rozpoczyna się dopiero w XVI stuleciu. Część z nich ma wcześniejszą, średniowieczną tradycję. Słownik staropolski zaświadcza, że takich określeń jest $14^{12}$. I tak - bartodziej 'pasiecznik, dozorca barci’ najstarsze potwierdzenie ma w Kazaniach gnieźnieńskich (Sstp 1: 68 ${ }^{13}$ ). Cegielnik w znaczeniu 'ceglarz' zapisany został w Księgach przyjęć do prawa miejskiego w Krakowie już XIV wieku - w 1392 roku (Sstp 1: 217). Farbierz 'rzemieślnik folujący i barwiący sukno' poświadczony jest w średniowiecznych zabytkach kilkakrotnie, a najstarsze potwierdzenie to zapis we wspominanych już Księgach przyjęć do prawa miejskiego w Krakowie z 1438 roku (Sstp 2: 356). Golicz 'ten, co goli' wyekscerpowany został z kazań średniowiecznych z II połowy XV wieku oraz z Rozmyślania przemyskiego (Sstp 2: 451). Hutarz w znaczeniu 'właściciel huty lub człowiek pracujący w hucie (szklanej)' odnotowany był w Księgach sadowych ziemi krakowskiej w roku 1452 (Sstp 2: 547). Igielnika 'rzemieślnika wyrabiającego igły’ z kolei potwierdził zapis z roku 1458 w Acta consularia Posnaniensia (Sstp 3: 3). Kleszmyta czyli 'rzemieślnika trudniącego się wyrabianiem drobnych przedmiotów metalowych, ślusarza' zapisano natomiast dwukrotnie w Księdze skarbowej Janusza, księcia mazowieckiego w roku 1482 oraz pod koniec XV wieku, w roku 1496 w kodeksie epistolarnym (Sstp 3: 287). Kocielnik 'rzemieślnik wyrabiający z metalu kotły itp. przedmioty, kotlarz, blacharz' najstarsze potwierdzenie ma w roku $1467 \mathrm{w}$ Księgach przyjęć do prawa miejskiego w Krakowie (Sstp 3: 312). Także łamacza jako 'robotnika wydobywającego kamienie w górach lub obrabiającego, ociosującego je' zapisano w średniowieczu kilka razy, najwcześniej w początkach XV stulecia w roku 1408 w Rachunkach z prac budowlanych na zamku w Nowym Mieście Korczynie (Sstp 4: 95). Podobnie odnaleziono w piętnastowiecznych zabytkach kilka zapisów 'rzemieślnika wyrabiającego noże' czyli nożownika, najstarsze w pisanej w latach 1418-1475 Księdze ławniczej Brześcia Kujawskiego (Sstp 5: 300). Okiennik 'rzemieślnik trudniący się wyrobem okien' potwierdzony jest zapisem z roku 1444 z Ksiag przyjęć do prawa miejskiego w Krakowie (Sstp 5: 550). Olejarz czyli ‘ten co wyrabia albo sprzedaje olej' po raz pierwszy zapisany został w 1449 w księdze ławniczej (Sstp 5: 569), a olejownik jako 'ten co wyrabia albo sprzedaje olej’ wystąpił w połowie XV wieku w glosach polskich w rękopisie z łacińskimi kazaniami (Sstp 5: 569). Ostatnie hasło powroźnik czyli ‘ten, co wyrabia powrozy’ zapisane zostało w średniowieczu kilkakrotnie, a najstarszy zapis pochodzi z Ksieggi sądu najwyższego prawa niemieckiego na zamku krakowskim z roku 1414 (Sstp 6: 529).

Przyjrzyjmy się teraz, które z tych osobliwych nazw rzemieślników poświadczonych w szesnastowiecznych słownikach, funkcjonują we współczesnych zbiorach leksykograficznych, co dokumentują leksykony z końca XX i początku XXI wieku ${ }^{14}$. Oczywiście zdaję sobie sprawę, że braki w słowniku zarówno współczesnym, jak i dawnym, nie muszą wcale oznaczać, że nazwa rzemieślnika nie istniała czy nie istnieje w żywym języku,

12 Według SPXVI średniowieczną genezę ma także pytelnik, ale nie ma jednak takiego hasła w Sstp.

13 Lokalizując formy w słownikach wielotomowych, nie podaję roku wydania, ale numer tomu i stronę.

${ }^{14}$ Biorę pod uwagę następujące słowniki: Słownik współczesnego języka polskiego pod redakcją Bogusława Dunaja, Inny słownik języka polskiego pod redakcją Mirosława Bańki, Uniwersalny słownik języka polskiego pod redakcją Stanisława Dubisza, Praktyczny słownik współczesnej polszczyzny pod redakcją Haliny Zgółkowej, Słownik 100 tysięcy potrzebnych słów pod redakcją Jerzego Bralczyka. 
zwłaszcza $\mathrm{w}$ jego odmianach specjalistycznych. Funkcjonowanie niepoświadczonej w słownikach leksyki rzemieślniczej udowodniła choćby Alicja Pihan-Kijasowa, badając Akty cechów wileńskich Pihan-Kijasowa 2010). Jak jednak zapowiedziałam, w tym artykule moim celem jest ukazanie leksykograficznych dziejów nazw rzemieślników poświadczonych w XVI stuleciu wyłącznie w słownikach.

Tak więc współczesne słowniki potwierdzają żywotność tylko niewielkiej części interesujących mnie leksemów. Wydaje się, że bez większych wątpliwości do tej grupy można zaliczyć następujące nazwy:

- cegielnik - PSWP: budowlany 'robotnik, który pracuje przy wyrobie cegieł' (6: 167), USJP: urz. 'robotnik wyrabiający cegły; ceglarz' (1: 375), Br: 'robotnik wyrabiający cegły' (77),

- miedziownik - PSWP: środowiskowy 'robotnik wykonujący wyroby z miedzi lub miedziujący przedmioty metalowe' (21: 114), USJP: rzem., techn. 'osoba, która zajmująca się wyrobem przedmiotów z miedzi lub miedziowaniem' (2: 634),

- młotnik - PSWP: 'robotnik zatrudniony do kucia młotem' (21: 354), USJP: zaw., techn. 'robotnik kujący młotem, np. przy ręcznej obróbce metalu' (2: 688), Br: 'robotnik kujący młotem' (369),

- powroźnik - PSWP: 'rzemieślnik, który trudni się wyrobem powrozów - grubych sznurków splecionych z włókien' (31: 381), USJP: rzem. 'rzemieślnik wyrabiający powrozy, liny, sznurki' (3: 472), Br: 'rzemieślnik wyrabiający powrozy, liny, sznurki' (618),

- pszczelarz - PSWP: 'osoba, która trudni się hodowlą pszczół...' (35: 11-12), USJP: pszcz. 'hodowca pszczół, specjalista w dziedzinie pszczelarstwa' (3: 840), SWJP: 'człowiek zajmujący się pszczelarstwem; specjalista w zakresie pszczelarstwa' (2: 213), Br: derywat przy haśle pszczelarstwo, ISJP: pszczelarz to osoba zajmująca się hodowaniem pszczół (2: 392).

Przy kilku hasłach pojawiły chronologiczne kwalifikacje wskazujące na to, że nazwy należą do dawnego, historycznego już słownictwa:

- bartodziej - PSWP: historyczny, pszczelarski 'człowiek, który wyrabiał barcie dla roju pszczół' (3: 289),

- igielnik - PSWP: dawny 'osoba zajmująca się wyrabianiem igieł, szpilek i haftek' (14: 119),

- nożownik - PSWP: dawny 'rzemieślnik wyrabiający noże' (24: 99), USJP: przest. 'rzemieślnik wyrabiający noże i inne narzędzia tnące' (2: 1031), SWJP: 'dawniej rzemieślnik robiący noże' (1: 624), Br: daw. 'rzemieślnik wyrabiający noże i inne narzędzia tnące' (469).

We współczesnych słownikach są także zamieszczone niektóre $\mathrm{z}$ wymienionych przeze mnie nazw rzemieślników, których jednak nie zaliczam do kontynuantów szesnastowiecznych osobliwości leksykograficznych. Mają one bowiem inną budowę lub występują w innych znaczeniach. Przykładowo:

- cieśla nie oznacza 'rzemieślnika zajmującego się obróbką kamienia, kamieniarza', ale 'rzemieślnika zajmującego się ręczną obróbką drewna, wykonującego drewniane konstrukcje budowlane' (USJP 1: 469),

- pobielacz to 'rzemieślnik zajmujący się pokrywaniem powierzchni metalowych, zwłaszcza kotłów, powłoka cyny w celu zabezpieczenia ich przed korozją' (PSWP 29: 178), a nie 'tynkarz', 
- o dtubaczu mówi się jako 'o kimś, kto wykonuje zbyt drobiazgowo jakaś czynność lub zajmuje się wąską dziedziną' (USJP 1: 617), a nie jest to 'ten, który drąży, żłobi',

- według SPXVI łatacz był synonimem krawca i odnosił się do 'naprawiającego zniszczoną odzież', a w PSWP jest potocznym określeniem 'człowieka, który łata; szewca zajmującego się łataniem, reperowaniem starego obuwia' (19: 430),

- łamacz nie jest kamiennym cieśla, ale 'pracownikiem drukarni zajmującym się łamaniem szpalt; metrampażem’ (USJP 2: 492),

- farbiarz (np. PSWP 11: 188) to jednak nie farbarz czy farbierz, przędzacz (Br 669) to nie przędacz, blacharz (np. USJP 1: 275) to nie blachmistrz czy blachownik.

Na zakończenie chcę jeszcze raz zaznaczyć, że zdaję sobie oczywiście sprawę, iż słowniki - co zresztą powszechnie wiadomo - nie są idealnym źródłem wiedzy o jakichkolwiek elementach leksykalnych (np. Handke 1975: 153). Przede wszystkim należy mieć świadomość tego, iż wielu leksykografów uzurpowało sobie prawo do kształtowania języka zgodnie z własnymi poglądami i wyobrażeniami (np. Bańko 2001: 18). Przegląd funkcjonowania osobliwych szesnastowiecznych „słownikowych” nazw rzemieślników w leksykograficznych zbiorach zarówno tych odnotowujących poświadczoną w staropolszczyźnie leksykę, jak i w słownikach współczesnych, pokazał jednak, że część z tych określeń nie stanowiła wyłącznie oryginalnych pomysłów - wytworów szesnastowiecznych słownikarzy, ale prawdopodobnie należała do rzeczywiście funkcjonującej ówczesnej, być może specjalistycznej leksyki.

\section{Bibliografia}

Bajerowa I., 1980, Wpływ techniki na ewolucję języka polskiego, Kraków.

Bańko M., 2001, Z pogranicza leksykografii i językoznawstwa. Studia o słowniku jednojęzycznym, Warszawa.

$\mathrm{Br}$ - Stownik 100 tysięcy potrzebnych słów, red. J. Bralczyk, Warszawa 2005.

Handke K., 1975, O „sztucznych” formach stowotwórczych $w$ stownikach, „Studia z Filologii Polskiej i Słowiańskiej” 15, s. 153-157.

ISJP - Inny słownik języka polskiego PWN, red. M. Bańko, t. 1-2, Warszawa 2000.

Migdał J., 2015, Dzieje wybranych szesnastowiecznych nazw rzemieślników w polszczyźnie, w: Języki słowiańskie w procesie przemian, red. G. Olchowa, M. Balowski, Banská Bystrica, s. 85-93.

Migdał J., 2016, Nazwy rzemieślników w szesnastowiecznym języku polskim na podstawie Słownika polszczyzny XVI wieku, w: Dialog z tradycja V. Językowe dziedzictwo kultury materialnej, red. E. Młynarczyk, E. Horyń, Kraków, s. 131-142.

Młynarczyk E., 2013, Nie święci garnki lepią. Obraz rzemiosła utrwalony w polskiej frazeologii, Kraków.

Opis źródet Słownika staropolskiego, 2005, red. W. Twardzik, Kraków.

Pihan-Kijasowa A., 2010, Wileńskie stownictwo rzemieślnicze XVI-XVIII wieku. Rekonesans badawczy, w: Językowe i kulturowe dziedzictwo Wielkiego Księstwa Litewskiego. Księga jubileuszowa na 1000-lecie Litwy, red. J. Mędelska, Z. Sawaniewska-Mochowa, Bydgoszcz, s. 334-341.

PSWP - Praktyczny stownik współczesnej polszczyzny, red. H. Zgółkowa, t. 1-50, Poznań 1994-2005.

SPXVI - Słownik polszczyzny XVI wieku, red. M. R. Mayenowa, F. Pepłowski, K. Mrowcewicz,

t. I-XXXVI, Wrocław - Warszawa - Kraków 1966-2012.

Sstp - Stownik staropolski, red. S. Urbańczyk, t. 1-11, Kraków 1953-2002.

SWJP - Słownik wspótczesnego języka polskiego, red. B. Dunaj, t. 1-2, Warszawa 1998. 
USJP - Uniwersalny słownik języka polskiego, red. S. Dubisz, t. 1-4, Warszawa 2003.

\section{Wykaz pozostałych skrótów:}

BartBygd - Bartłomiej z Bydgoszczy, Vocabularius ex Calepino, Breuiloquo et Mamotrecto reccolectus..., (Stownik tacińsko-polski), 1532.

Calep - Ambrosius Calepinus, Dictionarium decem linguarum, Lugdunum 1588.

Mącz - Jan Mączyński, Lexicon latino- polonicum, Królewiec 1564.

Murm - Jan Murmelius, Dictionarius [...] Rozmaitych rzeczy wokabuly łacińskie z niemieckiem i polskim wyktadem, Kraków 1528.

Mym - Franciscus Mymer, Dictionarium trium linquarum: Latino, Teutonice et Polonice, Kraków 1528 oraz Kraków 1541.

Volck - Mikołaj Volckmar, Dictionarium trilingue tripartitum, Gdańsk 1596.

\section{JOLANTA MIGDAL}

\section{Peculiar vocabulary in 16th century lexicons (selected examples of names of craftsmen)}

\section{Summary}

The article presents names of craftsmen which existed in the 16th century Polish language, confirmed exclusively in lexicographic collections of the time. The material has been drawn from the published volumes of Słownik polszczyzny XVI wieku (Dictionary of 16th century Polish language).

A review was conducted of the way in which these peculiar names of craftsmen functioned in the lexicons, both reflecting vocabulary confirmed in Old Polish and in contemporary dictionaries.

It turned out that even though some of these words were perhaps the original products of the 16th lexicographers' imaginations, others were actually used in the vocabulary of those times.

Keywords: diachronic linguistics, lexicography, sixteenth-century vocabulary, craftsman 